\section{BMJ Paediatrics Open}

\title{
Hypothermia on admission to a neonatal intensive care unit in Oromia, western Ethiopia: a case-control study
}

\author{
Bikila Girma (D), Belachew Etana Tolessa, Tariku Tesfaye Bekuma (D) , \\ Bikila Regassa Feyisa
}

To cite: Girma B, Tolessa BE, Bekuma TT, et al. Hypothermia on admission to a neonatal intensive care unit in Oromia, western Ethiopia: a case-control study. BMJ Paediatrics Open 2021:5:e001168. doi:10.1136/ bmjpo-2021-001168

- Additional supplemental material is published online only. To view, please visit the journal online (http://dx.doi.org/ 10.1136/bmjpo-2021-001168)

Received 21 May 2021 Accepted 17 September 2021

\section{Check for updates}

C) Author(s) (or their employer(s)) 2021. Re-use permitted under CC BY-NC. No commercial re-use. See rights and permissions. Published by BMJ.

Department of Public Health, Wollega University, Nekemte, Ethiopia

Correspondence to Bikila Girma; bikogirma1@ gmail.com

\section{ABSTRACT}

Objective Hypothermia is believed to affect more than half of Ethiopian neonates. The goal of this study is to determine risk factors for newborn hypothermia in neonates admitted to public hospitals in the east Wollega zone of western Ethiopia's neonatal intensive care unit. Design Unmatched case-control study using neonates admitted to the intensive care unit.

Setting Neonatal intensive care units at public hospitals in western Ethiopia.

Patients Neonates admitted to intensive care units. Main outcomes The cases were all neonates with hypothermia (less than $36.5^{\circ} \mathrm{C}$ ) and the controls were all neonates with a body temperature of greater or equal to $36.5^{\circ} \mathrm{C}$ when admitted to the neonatal intensive care unit for other reasons.

Results The study involved the participation of 73 cases and 146 controls. The study found that delayed breastfeeding initiation after 1 hour (adjusted OR $(\mathrm{AOR})=3.72 ; 95 \% \mathrm{Cl}$ : 1.39 to 10.00 ), admission weight less than $2500 \mathrm{~g}(\mathrm{AOR}=3.43 ; 95 \% \mathrm{Cl}: 1.18$ to 9.97$)$, cardiopulmonary resuscitation at birth $(\mathrm{AOR}=3.42 ; 95 \% \mathrm{Cl}$ : 1.16 to 10.10 .08 ), lack of immediate skin-to-skin contact with their mother ( $\mathrm{AOR}=4.54 ; 95 \% \mathrm{Cl}: 1.75$ to 11.81 ), night-time delivery (AOR=6.63; 95\% Cl: 2.23 to 19.77) and not wearing a cap (AOR=2.98; 95\% Cl: 1.09 to 8.15) were all associated with newborn hypothermia.

Conclusions Neonatal hypothermia was associated with obstetric, neonatal and healthcare provider factors. As a result, special consideration should be given to the thermal care of low birthweight neonates and the implementation of warm-chain principles with low-cost thermal protection in Ethiopian public health facilities.

\section{INTRODUCTION}

Neonatal hypothermia is the decrease of an axillary body temperature of the newborn below $36.5^{\circ} \mathrm{C}\left(97.7^{\circ} \mathrm{F}\right)$. It is classified as mild (cold stress) with body temperature between $36.0^{\circ} \mathrm{C}$ and $36.4^{\circ} \mathrm{C}\left(96.8^{\circ} \mathrm{F}-97.5^{\circ} \mathrm{F}\right)$, moderate between $32.0^{\circ} \mathrm{C}$ and $35.9^{\circ} \mathrm{C}\left(89.6^{\circ} \mathrm{F}-96.6^{\circ} \mathrm{F}\right)$ and below $32^{\circ} \mathrm{C}\left(<89.6^{\circ} \mathrm{F}\right)$ as severe hypothermia.

Hypothermia occurs when the body's physiological systems, such as vasoconstriction, shivering, muscle contraction and nonshivering thermogenesis, are no longer able
What is known about the subject?

$\Rightarrow$ Within the first 10-20 min of birth, neonates can lose up to $2^{\circ} \mathrm{C}$ of their body temperature if sufficient thermal care is not provided.

$\Rightarrow$ In resource-constrained countries, hypothermia increases newborn mortality by five times during the first 7 days of life.

$\Rightarrow$ Neonatal mortality in Ethiopia was disproportionately high, ranging from 22.1 to 62.5 per 1000 live births.

\section{What this study adds?}

$\Rightarrow$ Neonatal hypothermia is associated with lack of skin-to-skin contact soon after birth or a delay in starting breast feeding.

$\Rightarrow$ Low birth weight, not wearing a cap, cardiopulmo nary resuscitation, getting delivered at night and being preterm were all associated with newborn hypothermia in the study.

to maintain a normal core temperature Because of their higher surface area per unit body weight, large head in comparison with body and lack of subcutaneous fat (low birth weight), newborns are more likely to suffer hypothermia. $^{12}$

If adequate heat care is not provided soon after birth, newborns can lose heat by conduction, convection, evaporation and radiation, resulting in a drop in body temperature of up to $2^{\circ} \mathrm{C}$ within the first $10-20 \mathrm{~min} .^{3}$ Neonates' deep body and skin temperatures can also drop at a pace of $0.1^{\circ} \mathrm{C}$ and $0.3^{\circ} \mathrm{C}$ per minute, respectively. ${ }^{45}$

Neonatal mortality is more common in resource-constrained nations, where hypothermia is the leading cause of death. ${ }^{6} 7$ According to a research, every $1^{\circ} \mathrm{C}$ drop in body temperature increases mortality by $80 \%{ }^{8}$ Hypothermia has been identified as a substantial contributor to the worldwide 
burden of newborn fatalities in sub-Saharan African nations, according to the literature. ${ }^{9-18}$

Between 1990 and 2015, the under-5 mortality rate in African countries fell considerably. ${ }^{8}{ }^{19}$ The rate of newborn mortality in Ethiopia has decreased from 37 to 29 fatalities per 1000 live births, according to the Ethiopian Demographic Health Survey (EDHS) 2016 report. This rate varies by area, with Addis Ababa having the lowest rate at 18 fatalities per 1000 live births and Amhara having the highest rate at 47 deaths per 1000 live births. ${ }^{20}$ However, according to the mini-EDHS 2019, the newborn mortality rate increased marginally from 29 to 30 fatalities per 1000 live births from 2016 to $2019 .^{21}$

Several factors have been linked to the occurrence of hypothermia in newborns, according to research. These factors were correlated to maternal and neonatal features, as well as environmental and healthcare system characteristics. ${ }^{711}$ The results of previous Ethiopian studies on this topic have been equivocal. ${ }^{22-27}$

Despite the fact that predisposing factors for hypothermia are easily preventable, and several activities and intervention techniques have been devised to reduce the risk of hypothermia, the problem remains unsolved, and it is extremely common in Ethiopia (53\%). ${ }^{1128}$ As a result, the goal of this study was to determine the risk factors for newborn hypothermia in neonates born in hospitals in the east Wollega zone of western Ethiopia.

\section{PATIENTS AND METHODS}

\section{Study area and subjects}

The research was conducted at public hospitals in east Wollega zone, Oromia Region, western Ethiopia, which has a population of 1598809 people, 795618 men and 803191 women, and covers an area of $12579.77 \mathrm{~km}^{2}{ }^{29}$ Nekemte Specialized Hospital, Wollega University Referral Hospital, Arjo Hospital, Gida Ayana and Sire Hospital are the five public hospitals in the province. The neonatal intensive care unit (NICU) is one of the units in these hospitals where all neonates under the age of 28 days were admitted. It includes newborns referred from the labour ward and other surrounding health facilities.

A hospital-based unmatched case-control study design was conducted from 30 February to 30 April 2020. All neonates and their mothers/caregivers admitted to public hospitals in the east Wollega zone of western Ethiopia served as the study's source population.

Cases were neonates with an axillary body temperature of less than $36.5^{\circ} \mathrm{C}$ at admission to the NICU during the study period at public hospitals in the east Wollega zone. ${ }^{1}$

Controls were neonates admitted to the NICU during the study period who did not have hypothermia or an axillary body temperature of greater or equal to $36.5^{\circ} \mathrm{C}$. ${ }^{1}$

All neonates admitted to NICUs in public hospitals in east Wollega zone within 28 days of delivery, regardless of where they were born, were included in the study, while newborns with serious congenital malformations were omitted.

\section{Sample size and sampling procedures}

Using Epi Info V.7.1.3.10 software, the sample size for an unmatched case-control study was estimated using assumptions of a double population proportion formula. Low birth weight $2500 \mathrm{~g}$, preterm (37 weeks), APGAR score at $5 \mathrm{~min}$ and commencement of breast feeding within 1 hour were deemed decisive variables to attain the maximal sample size in earlier studies. ${ }^{25}$ Finally, the primary exposure variable was the proportion of controls who started breast feeding within 1 hour. As a result, the final sample size was 219 neonates and their mothers/ caregivers (73 cases and 146 controls), which was the largest sample size estimated.

The study subjects were chosen using a consecutive selection procedure from five public hospitals during the course of the study period until the predetermined sample size was reached. Cases and controls were chosen from the same health facility on consecutive days. Based on cases received from the NICU registration book in the previous 2 months of the study, the sample was proportionally allocated to each study site. During the study period, we did not encounter a mother with two or more babies for this particular study.

\section{Data collection tools and data collectors}

The data collection questionnaire was written in English and subsequently translated into Afaan Oromo, the regional working language. Using structured questionnaires presented by an interviewer, data were obtained from mothers, newborns and charts of neonates admitted to the NICU (online supplemental appendix). Two Bachelor of Science nurses and three midwives who have previous experience of data collection and can fluently speak Afaan Oromo were recruited from maternal and child health department to collect the data. Three supervisors were on hand during the data collection period to provide continuous follow-up and supervision. To distinguish cases from controls, a digital thermometer was used, which measured the surface temperature at the axilla location in accordance with WHO recommendations.

Prior to data collection, a pretest was performed on $5 \%$ of neonates admitted to the NICU at Shambu Hospital. The tool's reliability was tested, yielding a Cronbach's alpha of 0.73. Data collectors and supervisors received 2 days of training on how to collect data. The measurement was then double-checked with reference thermometers every day to avoid any misleading readings caused by thermometer deterioration. Following data collection, supervisors and the principal investigator reviewed and checked the questionnaires for completeness on a regular basis. To limit the possibility of data-entering errors, EpiData V.3.1 was employed. Each and every questionnaire was cross-checked with the entered data and all observed errors were corrected.

\section{Variables \\ Dependent variable: neonatal hypothermia.}


Independent variables: maternal sociodemographic/ economic determinants, neonatal-related determinants, neonatal caring practices, obstetric determinants.

\section{Statistical analysis and processing}

Data were entered into EpiData V.3.1, cleaned and doublechecked for completeness and consistency, and exported to SPSS Windows V.25.0 for analysis. A bivariable analysis was performed to identify candidate variables associated with neonatal hypothermia, and variables with $\mathrm{p}$ values less than 0.25 were transferred for multivariable logistic regression to determine hypothermia risk factors (online supplemental tables 1 and 2). The model's goodness of fit was evaluated using the Hosmer-Lemeshow test, which yielded a $p$ value of $\geq 0.05$. Variance inflation factors were used to test the variables' multicollinearity. The analysis was adjusted for mother's age. Crude and adjusted ORs with a $95 \%$ CI and a $p$ value of $<0.05$ were considered statistically significant.

\section{Patient and public involvement}

Neither patients nor the public were involved in the design, analysis and interpretation of this study and will not be involved in the dissemination of the results.

\section{RESULTS}

Sociodemographic/economic characteristics of mothers

In this study, 73 neonates who had hypothermia with their mothers (cases) and 146 neonates who did not have hypothermia with their mothers (controls) were included. The mean age of the mothers in cases was 24.88 years ( $\mathrm{SD} 4.39$ ), and the age of the mothers in controls was 25.62 years (SD 4.69). Thirty-six (49.3\%) of case mothers and $76(52.1 \%)$ of control mothers lived in rural areas (table 1$)$.

\section{Factors associated with neonatal hypothermia}

According to this study, the odd of hypothermia was 3.43 times higher in those weighing less than $2500 \mathrm{~g}$ compared with those weighing more than $2500 \mathrm{~g}$ (adjusted OR $(\mathrm{AOR})=3.43 ; 95 \% \mathrm{CI}: 1.18$ to 9.97$)$. Birth resuscitation was also a significant risk factor for neonatal hypothermia. The odds of hypothermia were 3.42 times higher among those who were resuscitated at birth (cardiopulmonary resuscitation (CPR)) compared with those who did not (AOR=3.42; 95\% CI: 1.16 to 10.08$)$.

Furthermore, the odd of hypothermia was 3.72 times (AOR=3.72; 95\% CI: 1.39 to 10.00) higher among neonates who were initiated breast feeding compared with those who were initiated before 1 hour after birth. Similarly, the odd of hypothermia was more than three times higher in those who do not wear cap than controls (AOR $=2.98 ; 95 \%$ CI: 1.09 to 8.15$)$.

Lack of skin-to-skin contact with mothers after delivery was another significant determinant of neonatal hypothermia. Those who do not have skin-to-skin contact with their mother after birth were 4.54 times higher to develop hypothermia compared with their counterparts (AOR $=4.54 ; 95 \%$ CI: 1.75 to 11.81 ). Also, the odd of developing hypothermia was about seven times higher in those who were born during the night compared with those who were born during the day $(\mathrm{AOR}=6.63 ; 95 \% \mathrm{CI}$ : 2.23 to 19.77 ) (table 2 ).

\section{DISCUSSION}

One of the risk factors for newborn hypothermia, according to this study, was delayed commencement of breast feeding. This finding is supported by research from Tigray, north Ethiopia, Zambia and southern Nepal. ${ }^{25} 3031$ The association could be related to the fact that early breast feeding allows babies to have more skin-to-skin contact with their mothers, prevents the newborn from being exposed to the environment and increases mothers' follow-up care for their babies, all of which help to prevent hypothermia. ${ }^{32}$ Another reason could be that breastfed newborns obtain enough calories from their mother's milk, which produces heat for thermoregulation, so the more they are breast fed, the more glucose they get to meet their energy needs. ${ }^{33}$ Lack of skin-to-skin contact with their mother shortly after birth was another significant risk factor for newborn hypothermia in this study, which supports this finding. The findings are also supported by the literature. ${ }^{22} 3134$ This is because newborns who do not have skin-to-skin contact with their mothers lose more heat through conduction, even when their mother's external body temperature is nearly identical to their womb temperature. ${ }^{35}$ Furthermore, skin-to-skin contact is more successful than incubator care for rewarming the infant because the maternal chest and abdomen movement promotes the newborn to breathe more deeply, which improves heat generation via oxidative phosphorylation. ${ }^{1}$

This finding, however, contradicted other Ethiopian findings. ${ }^{23}$ This variance could be related to differences in delivery location, study context and study methodology. According to the study, all mothers delivered at health facilities, although $9.1 \%$ of the mothers delivered at home in this study.

Low birth weight at admission was found to be a risk factor for newborn hypothermia in this study. This finding is consistent with research done in Ethiopia's Arba Minch, South Nations and Nationalities, and Gondar, Amhara area. ${ }^{24} 26$ This conclusion was also corroborated by research undertaken in Iran and Pakistan. ${ }^{36}{ }^{37}$ This could be due to a variety of factors, including radiant heat loss (when bare skin is exposed to a cooler environment), evaporative heat loss (when neonates are wet with amniotic fluid shortly after birth), conductive heat loss (when neonates are placed in contact with a cool surface or object) and convective heat loss (when a flow of cooler ambient air carries heat loss, a flow of cooler ambient air carries heat away from the neonate) ${ }^{2}$

The timing of delivery was also revealed to be a risk factor for newborn hypothermia in this study. Those whose mothers gave birth at night had a greater chance 
Table 1 Sociodemographic and economic characteristics of mothers for neonates admitted at public hospitals of east Wollega zone, western Ethiopia, February-April 2020

\begin{tabular}{|c|c|c|c|c|c|}
\hline \multirow[b]{2}{*}{ Variables } & \multirow{2}{*}{$\begin{array}{l}\text { Cases } \\
n=73(\%)\end{array}$} & \multirow{2}{*}{$\begin{array}{l}\text { Control } \\
n=146(\%)\end{array}$} & \multirow{2}{*}{$\begin{array}{l}\text { Total } \\
\mathrm{n}=219(\%)\end{array}$} & \multirow{2}{*}{$\begin{array}{l}\text { Crude OR } \\
(95 \% \mathrm{Cl})\end{array}$} & \multirow[b]{2}{*}{$P$ value } \\
\hline & & & & & \\
\hline \multicolumn{6}{|l|}{ Age of respondent } \\
\hline $15-19$ & $7(9.6)$ & $13(8.9)$ & $20(9.1)$ & 1.14 (0.38 to 3.37$)$ & 0.81 \\
\hline 20-29 & $49(67.1)$ & $97(66.4)$ & $146(66.7)$ & 1.07 (0.55 to 2.09$)$ & 0.84 \\
\hline 30-39 & 17 (23.3) & $36(24.7)$ & $53(24.2)$ & 1 & \\
\hline \multicolumn{6}{|l|}{ Residence } \\
\hline Urban & $37(50.7)$ & $70(47.9)$ & 107 (48.9) & 1 & \\
\hline Rural & $36(49.3)$ & $76(52.1)$ & $112(51.1)$ & 0.90 (0.51 to 1.57$)$ & 0.7 \\
\hline \multicolumn{6}{|l|}{ Ethnic group } \\
\hline Oromo & $54(74)$ & $114(78.1)$ & $168(76.7)$ & 1 & \\
\hline Amhara & $14(19.2)$ & $26(17.8)$ & 40 (18.3) & 1.14 (0.55 to 2.35$)$ & 0.73 \\
\hline Other* & $5(6.8)$ & $6(4.1)$ & $11(5)$ & 1.76 (0.51 to 6.02$)$ & 0.37 \\
\hline \multicolumn{6}{|l|}{ Religion } \\
\hline Orthodox & $19(26)$ & 48 (32.9) & $67(30.6)$ & 1 & \\
\hline Protestant & $45(61.6)$ & $81(55.5)$ & $126(57.5)$ & 1.40 (0.74 to 2.67$)$ & 0.3 \\
\hline Muslim & $9(12.3)$ & $17(11.6)$ & $26(11.9)$ & 1.34 (0.51 to 3.52$)$ & 0.56 \\
\hline \multicolumn{6}{|l|}{ Educational status } \\
\hline Can't read and write & $18(24.7)$ & $30(20.5)$ & 48 (21.9) & $2.06(0.74$ to 5.73$)$ & $0.17 \dagger$ \\
\hline Grade 1-8 & $31(42.5)$ & $59(40.4)$ & $90(41.1)$ & $1.80(0.70$ to 4.65$)$ & $0.22 \dagger$ \\
\hline Grade 9-12 & 17 (23.3) & 33 (22.6) & $50(22.8)$ & 1.77 (0.63 to 4.92$)$ & 0.28 \\
\hline College and above & $7(9.6)$ & $24(16.4)$ & $31(14.2)$ & 1 & \\
\hline \multicolumn{6}{|l|}{ Occupation } \\
\hline Housewife & $29(39.7)$ & $56(38.4)$ & $85(38.8)$ & 1.15 (0.53 to 2.49$)$ & 0.73 \\
\hline Private business & $18(24.7)$ & 33 (22.6) & $51(23.3)$ & 1.21 (0.52 to 2.84$)$ & 0.66 \\
\hline Government employee & $12(16.4)$ & $26(17.8)$ & $38(17.4)$ & 1.02 (0.40 to 2.59$)$ & 0.96 \\
\hline Farmer & $14(19.2)$ & 31 (21.2) & $45(20.5)$ & 1 & \\
\hline \multicolumn{6}{|l|}{ Family size } \\
\hline $1-3$ & $26(35.6)$ & $54(37)$ & $80(36.5)$ & 1 & \\
\hline $4-6$ & $43(58.9)$ & $78(53.4)$ & $121(55.3)$ & 1.69 (0.51 to 5.63$)$ & 0.4 \\
\hline$>6$ & $4(5.5)$ & $14(9.6)$ & $18(8.2)$ & $1.93(0.60$ to 6.23$)$ & 0.27 \\
\hline \multicolumn{6}{|c|}{ Distance to reach health facility } \\
\hline$<30 \min$ & $23(31.5)$ & $51(34.9)$ & $74(33.8)$ & 1 & \\
\hline $30-60 \mathrm{~min}$ & $33(45.2)$ & 57 (39) & $90(41.1)$ & 1.01 (0.47 to 2.14$)$ & 0.98 \\
\hline$>60 \min$ & 17 (23.3) & $38(26)$ & $55(25.1)$ & 1.30 (0.63 to 2.65$)$ & 0.48 \\
\hline \multicolumn{6}{|l|}{ Wealth index status } \\
\hline Poor & $41(56.2)$ & 34 (23.3) & 75 (34.2) & 5.15 (2.50 to 10.60$)$ & $0.01 \dagger$ \\
\hline Medium & 18 (23.3) & $48(32.9)$ & 65 (29.7) & 1.51 (0.66 to 3.33 ) & 0.31 \\
\hline Rich & $15(20.5)$ & $64(43.8)$ & 79 (36.1) & 1 & \\
\hline
\end{tabular}

*Gurage and Tigre.

†Variables that showed significant association during bivariable analysis.

of experiencing hypothermia than those whose mothers gave birth during the day. This is supported by research from Gondar, northwest Ethiopia, Tigray, north Ethiopia and Uganda. ${ }^{25} 2638$ This could be owing to the fact that night-time room temperatures are lower than daytime temperatures, or it could be due to temperature differences between night and day. ${ }^{39}$ Additionally, work overload during the night could be a factor, as the number of staff 
Table 2 Factors associated with neonatal hypothermia among neonates admitted at neonatal intensive care units in hospitals of east Wollega zone, Ethiopia; February-April 2020

\begin{tabular}{|c|c|c|c|c|}
\hline \multirow[b]{2}{*}{ Variables } & \multirow{2}{*}{$\begin{array}{l}\text { Cases } \\
n=73(\%)\end{array}$} & \multirow{2}{*}{$\begin{array}{l}\text { Controls } \\
n=176(\%)\end{array}$} & \multirow{2}{*}{$\begin{array}{l}\text { Crude OR } \\
(95 \% \mathrm{Cl})\end{array}$} & \multirow[b]{2}{*}{ Adjusted OR (95\% Cl) } \\
\hline & & & & \\
\hline \multicolumn{5}{|c|}{ Weight of newborn at admission } \\
\hline$<2500 \mathrm{~g}$ & $30(41.1)$ & $12(8.2)$ & 7.79 (3.67 to 16.53$)$ & $3.43(1.18 \text { to } 9.97)^{\star}$ \\
\hline$\geq 2500 \mathrm{~g}$ & $43(58.9)$ & $134(91.8)$ & 1 & 1 \\
\hline \multicolumn{5}{|c|}{ Cardiopulmonary resuscitation done } \\
\hline Yes & $64(87.7)$ & $70(47.9)$ & 7.72 (3.58 to 16.67$)$ & $3.42(1.16 \text { to } 10.08)^{\star}$ \\
\hline No & $9(12.3)$ & $76(52.1)$ & 1 & 1 \\
\hline \multicolumn{5}{|c|}{ Initiation of breast feeding at birth } \\
\hline Immediately & $16(21.9)$ & $81(55.5)$ & 1 & 1 \\
\hline Within 1 hour & $10(13.7)$ & $39(26.7)$ & $1.30(0.54$ to 3.12$)$ & 1.64 (0.57 to 4.68$)$ \\
\hline After 1 hour & $47(64.4)$ & $26(17.8)$ & 9.15 (4.46 to 18.78$)$ & $3.72(1.39 \text { to } 10.00)^{\star}$ \\
\hline \multicolumn{5}{|c|}{ Head covered with cap at birth } \\
\hline Yes & $43(58.9)$ & $120(82.2)$ & 1 & 1 \\
\hline No & $30(41.1)$ & $26(17.8)$ & 3.22 (1.72 to 6.05$)$ & $2.98(1.09 \text { to } 8.15)^{\star}$ \\
\hline \multicolumn{5}{|c|}{ Skin-to-skin contact present at birth } \\
\hline Yes & $29(39.7)$ & $128(87.7)$ & 1 & 1 \\
\hline No & $44(60.3)$ & $18(12.3)$ & 10.79 (5.46 to 21.31$)$ & $4.54(1.75 \text { to } 11.81)^{\star}$ \\
\hline \multicolumn{5}{|l|}{ Time of delivery } \\
\hline Day & 9 (12.3) & 86 (58.9) & 1 & 1 \\
\hline Night & $64(87.7)$ & $60(41.1)$ & $10.19(4.71$ to 22.05$)$ & $6.63(2.23 \text { to } 19.77)^{\star}$ \\
\hline \multicolumn{5}{|l|}{ Gestational age } \\
\hline$<37$ weeks & 26 (35.6) & $18(12.3)$ & 3.93 (1.98 to 7.83 ) & 2.80 (0.93 to 8.41$)$ \\
\hline$\geq 37$ weeks & $47(64.4)$ & $128(87.7)$ & 1 & 1 \\
\hline
\end{tabular}

working in the labour room at night is not equivalent to the number of staff working during the day.

Furthermore, neonatal hypothermia was associated with children who received CPR at birth. This result is consistent with research from Addis Ababa, Ethiopia, Iran and Bangladesh. $^{22} 3440$ This is because neonates who require resuscitation have undergone birth asphyxia; there is insufficient oxygen for mitochondrial oxidation in brown adipose tissue, which is required for heat production. ${ }^{2}$ In addition, temperature regulation during resuscitation at birth may not be effectively addressed; in an emergency, resuscitation may be performed without wrapping the newborn and on a cold surface. This result, however, is contradicted by a research conducted in Arba Minch, southwest Ethiopia. ${ }^{24}$ This discrepancy could be attributable to differences in thermal care during resuscitation, warm resuscitation, resuscitation period and study methodology.

Neonates who did not have their heads covered after delivery had a higher risk of developing hypothermia than those who did. This conclusion was similar to that of a research conducted in Harar, Ethiopia's eastern region. ${ }^{23}$ This could be owing to their huge skull, which has open fontanels and sutures, and contributes to nearly $25 \%$ of neonatal heat loss if not covered by a cap. ${ }^{3}$

Even though the study was conducted in different hospitals, it was only done for a short period or in one season, therefore considerations such as climatic changes or seasonal variations were not taken into account. Another drawback of this study was that hospital-related characteristics like the abilities and qualifications of healthcare personnel working in delivery rooms and NICUs, which may have been linked to hypothermia, were not taken into consideration. There could also be an effect of recall bias.

\section{CONCLUSIONS}

The study found that delayed breastfeeding initiation, neonatal weight less than $2500 \mathrm{~g}$ on admission, lack of skinto-skin contact with mothers at birth, cardiopulmonary situations at birth, being born at night and not wearing a cap immediately after birth were all significantly associated with neonatal hypothermia on admission to NICUs.

Acknowledgements We want to extend our gratitude to Wollega University, the data collectors and study participants. 
Contributors BG, BET, TTB and BRF conceptualised and designed the study, collected the data and wrote the results. BRF wrote the manuscript draft. BG $B E T$ and TTB reviewed the manuscript. All authors read and approved the final manuscript.

Funding The authors have not declared a specific grant for this research from any funding agency in the public, commercial or not-for-profit sectors.

Competing interests None declared.

Patient consent for publication Not required.

Ethics approval The study was approved by the Institutional Review Boards of Wollega University (ref no. DPH/362/2012). Written informed consent was obtained from the study participants.

Provenance and peer review Not commissioned; externally peer reviewed.

Data availability statement Data are available upon reasonable request. The data sets used for this study are available from the corresponding author on a reasonable request.

Supplemental material This content has been supplied by the author(s). It has not been vetted by BMJ Publishing Group Limited (BMJ) and may not have been peer-reviewed. Any opinions or recommendations discussed are solely those of the author(s) and are not endorsed by BMJ. BMJ disclaims all liability and responsibility arising from any reliance placed on the content. Where the content includes any translated material, BMJ does not warrant the accuracy and reliability of the translations (including but not limited to local regulations, clinical guidelines, terminology, drug names and drug dosages), and is not responsible for any error and/or omissions arising from translation and adaptation or otherwise.

Open access This is an open access article distributed in accordance with the Creative Commons Attribution Non Commercial (CC BY-NC 4.0) license, which permits others to distribute, remix, adapt, build upon this work non-commercially, and license their derivative works on different terms, provided the original work is properly cited, appropriate credit is given, any changes made indicated, and the use is non-commercial. See: http://creativecommons.org/licenses/by-nc/4.0/.

ORCID iDs

Bikila Girma http://orcid.org/0000-0002-7896-717X

Tariku Tesfaye Bekuma http://orcid.org/0000-0002-7390-1788

\section{REFERENCES}

1 World Health Organization. Thermal protection of the newborn:a practical guide. Geneva, 1997: 1-68.

2 Kliegman RNW. Nelson textbook of pediatrics. Philadelphia PA: Elsevier/Saunders, 2011.

3 WHO G. Thermal protection of the newborn: a practical guide. Maternal and safe motherhood unit, 2006.

4 Altimier L. Thermoregulation: What's New? What's Not? Newborn Infant Nurs Rev 2012;12:51-63.

5 Roya F, Mohammad SMN. Incidence of neonatal hypothermia at birth in hospitals of Islamic Republic of Iran: a systematic review. $J$ Pediatr 2014;2:2-6.

6 Sodemann M, Nielsen J, Veirum J, et al. Hypothermia of newborns is associated with excess mortality in the first 2 months of life in Guinea-Bissau, West Africa. Trop Med Int Health 2008;13:980-6.

7 Kambarami R, Chidede O. Neonatal hypothermia levels and risk factors for mortality in a tropical country. Cent Afr J Med 2003;49:103-6.

8 Liu L, Oza S, Hogan D, et al. Global, regional, and national causes of under-5 mortality in 2000-15: an updated systematic analysis with implications for the sustainable development goals. The Lancet 2016;388:3027-35.

9 United Nations. The Millennium Development Goals Report with more targets achievable by 2015 : UN report. New york, 2015.

10 Darmstadt GL, Tielsch JM. Risk of mortality associated with neonatal hypothermia in southern Nepal. Arch Pediatr Adolesc Med 2010;164. doi:10.1001/archpediatrics.2010.103

11 Lunze K, Bloom DE, Jamison DT, et al. The global burden of neonatal hypothermia: systematic review of a major challenge for newborn survival. BMC Med 2013;11:1-11.

12 Mance MJ. Foundation in newborn care,Keeping Infants Warm. In: Advances in neonatal care. 8, 2008.

13 Thairu L, Pelto G. Newborn care practices in Pemba island (Tanzania) and their implications for newborn health and survival. Matern Child Nutr 2008;4:194-208.
14 Biostatistics E. Neonatal Mortality and its risk factors in Eastern Ethiopia : A Prospective Cohort Study in Kersa Health and Demographic Surveillance System (Kersa HDSS) 2016;13:1-8.

15 Mengesha HG, Wuneh AD, Lerebo WT, et al. Survival of neonates and predictors of their mortality in Tigray region, Northern Ethiopia: prospective cohort study. BMC Pregnancy Childbirth 2016;16:1-13.

16 Demisse AG, Alemu F Gizaw MA, et al. Patterns of admission and factors associated with neonatal mortality among neonates admitted to the neonatal intensive care unit of University of Gondar Hospital, Northwest Ethiopia. Pediatric Health Med Ther 2017;8:57-64.

17 Seid SS, Ibro SA, Ahmed AA, et al. Causes and factors associated with neonatal mortality in neonatal intensive care unit (NICU) of Jimma University medical center, Jimma, South West Ethiopia. Pediatric Health Med Ther 2019;10:39-48.

18 Track B. Assessment of admission hypothermia as a marker of neonataldeath in neonates admitted to neonatal intensive care unit of Ethiopia. Ethiopia: Hawassa Referral Hospital, 2018: 1-54.

19 World Health Organization. Atlas of African health statistics. health situation analysis of the African region. Geneva, 2016.

20 Ethiopian centeral statistics Agency. Ethiopia Demographic and Health Survey. Addis Ababa,Ethiopia and Calverton. Maryland, USA: Central Statistical Agency and ICF International, 2016: 133-9.

21 TDP ICF, Rockville MU. Ethiopia mini demographic and health survey. Addis Ababa 2019:1-35.

22 Demissie BW, Abera BB, Chichiabellu TY, et al. Neonatal hypothermia and associated factors among neonates admitted to neonatal intensive care unit of public hospitals in Addis Ababa, Ethiopia. BMC Pediatr 2018;18:1-10.

23 Alebachew Bayih W, Assefa N, Dheresa M, et al. Neonatal hypothermia and associated factors within six hours of delivery in eastern part of Ethiopia: a cross-sectional study. BMC Pediatr 2019:19:1-11.

24 Ukke GG, Diriba K. Prevalence and factors associated with neonatal hypothermia on admission to neonatal intensive care units in Southwest Ethiopia - a cross-sectional study. PLoS One 2019;14:1-13.

25 Tasew H, Gebrekristos K, Kidanu K, et al. Determinants of hypothermia on neonates admitted to the intensive care unit of public hospitals of central zone, Tigray, Ethiopia 2017: unmatched case-control study. BMC Res Notes 2018;11:576.

26 Erekia Ebrahim TS. Proportion of neonatal hypothermia and associated factors among New-borns at Gondar university teaching and Refferal Hospital, Northwest Ethiopia: a hospital based cross sectional study. Gen Med 2015;03:1-7.

27 Lassi ZS. Rohail Kumar and Zab. community-based care to improve maternal, newborn, and child health, 2016: 1-22.

28 World Health Organization. Pocket book of hospital care for children. 2nd ed, 2013

29 Ababa A. Federal Democratic Republic of Ethiopia central statistical agency population projection of Ethiopia for all regions at Wereda level from 2014 - 2017, 2017

30 Mullany LC, Katz J, Khatry SK, et al. Neonatal hypothermia and associated risk factors among newborns of southern Nepal. BMC Med 2010;8:1-14.

31 Lunze K, Yeboah-Antwi K, Marsh DR, et al. Prevention and management of neonatal hypothermia in rural Zambia. PLoS One 2014;9:1-7.

32 Srivastava S, Gupta A, Bhatnagar A, et al. Effect of very early skin to skin contact on success at breastfeeding and preventing early hypothermia in neonates. Indian J Public Health 2014;58:22-6.

33 Knobel RB. Newborn \& Infant Nursing Reviews Fetal and Neonatal Thermal Physiology Durham, NC. , 2014: 14, 45-7.

34 Ogundeyi MM. Prevalence and risk factors for hypothermia on admission in Nigerian babies - $72 \mathrm{~h}$ of age. $\mathrm{J}$ Perinat Med doi:10.1515/JPM.2009.014

35 CMNRP. Newborn thermoregulation. Modul self learn, 2013: 3-10.

36 Zayeri F, Kazemnejad A, Ganjali M, et al. Incidence and risk factors of neonatal hypothermia at referral hospitals in Tehran, Islamic Republic of Iran. East Mediterr Health J 2007:13:1308-18.

37 Ali R, Mirza R, Qadir M. Neonatal hypothermia among hospitalized high risk newborns in a developing country. Pakistan J Med Sci 2012;28:1-6.

38 Byaruhanga R, Bergstrom A, Okong P. Neonatal hypothermia in Uganda: prevalence and risk factors. J Trop Pediatr 2005;51:212-5.

39 Mullany LC, Joanne Katz S. Incidence and seasonality of hypothermia among newborns in southern Nepal. Incid Seas hypothermia among newborns South Nepal 2015;164:1-16.

$40 \mathrm{Em} \mathrm{M}$, Alderdice $\mathrm{F}, \mathrm{HI} \mathrm{H}$. Interventions to prevent hypothermia at birth in preterm and / or low birth weight infants. Cochrane Database Syst Rev doi:10.1002/14651858.CD004210.pub5 